\title{
Intangible Cultural Heritage: Traditional Yi Embroidery Handicraft at Zhizuo and Its Characteristics
}

\author{
Dr. Linli Chen \\ Associate Professor \\ School of International Exchange \\ Yunnan Open University \\ China
}

\begin{abstract}
Yi Embroidery, one of intangible cultural heritages in China, has its own characteristics and implies certain cultural connotation. Different people has different understanding of cultural connotations on various embroidery patterns, however, the wish to pursuit for a better life is the same. Embroidery embodies not only national character, but also national cultural psychology of Yi people. By using bold color schemes and rich bright colors, Yi Embroidery of Zhizuo in Yunnan, one of the typical representations in Chinese traditional handicraft, can both reflect their unique national identity psychology, and express the harmony of man and nature.
\end{abstract}

Keywords: Yi embroidery, characteristics, connotation, Zhizuo

Embroidery, as a folk art with a long tradition, has an important position in the history of Chinese arts and crafts. It is one of the oldest and most beautiful crafts. Commonly known as "xiuhua"(embroidering flowers) in China, embroidery is cloth decorated with needlework and it is performed by using needle and colored thread (silk, cloth with soft nap, and thread) to prick and stitch fabrics including silk, satin, yarn, cloth, hemp and goatskin, etc. thus forming patterns or characters on the basis of embroidered trace. It has become one of intangible cultural heritages in China.

\section{History of embroidery}

China was the first country in the world to weave silk. Silkworms were domesticated as early as some 5,000 years ago. The production of silk threads and fabrics gave rise to the art of embroidery, which was applied to various costumes early 4000-5000 years ago. In 1958, a piece of silk embroidered with a dragon and phoenix was unearthed in Changsha, Hunan Province from the state of Chu tomb of the Warring Sates Period (475-221BC). More than 2,000 years old, it is the earliest and the most ancient piece of Chinese embroidery ever unearthed.

In the Qin-Han Period, embroidery and silk were the principal commodities transported on the Silk Road. Moreover, during the long time of feudal empire, embroidered armorial bearings on the gowns worn by the emperor and empress as well as officials of all ranks not only served as decorations, but also symbolized the wearer's status and ranks. Flower clusters embroidered on clothes of distinguished people are also an embodiment of the exquisite embroidery process.

\section{Embroidery styles in China}

\subsection{Major styles}

Embroidery is a technique generally favored by most Chinese people and silk embroidery is practiced nearly all over China. The Four Famous Embroideries of China are the Su embroidery (Su Xiu) in eastern China's Jiangsu Province, Xiang embroidery (Xiang Xiu) in central China's Hunan Province, Yue embroidery (Yue Xiu) in southern China's Guangdong Province and Shu embroidery (Shu Xiu) in western China's Sichuan Province. All of them have become Chinese Intangible Cultural Heritages with different characteristics.

Su embroidery features a strong, folk flavor. Xiang Embroidery emphasizes on contrasts of light and shade that highlight the pattern texture to give a three-dimensional effect. Influenced by national folk art, the embroidered pictures of Yue embroidery are mainly of dragons and phoenixes, and flowers and birds, with neat designs and strong, contrasting colors. The works of Shu embroidery incorporate flowers, leaves, animals, mountains, rivers and human figures as their themes, formed its smooth, bright and neat features. 


\subsection{Ethnic styles-- Yi embroidery}

In addition to the four major embroidery styles and some other styles, there are ethnic group embroidery styles, like Yi, Miao, Bai, Zhuang and Zang. They all have their own styles of embroidery. Among them, Yi embroidery is famous. Most of Yi people are talented in embroidery. Embroidery is usually used to reflect people's way to life, personality, particular tastes in fashion, color and design. There are more than 8 million Yi people in China according to the national statistic data in 2010. They live primarily in rural areas of Sichuan, Yunnan, Guizhou, and Guangxi, usually in mountainous regions, on the sides of steep mountain slopes far from the cities of China. Zhizuo, a typical Yi village of Yongren County in Chuxiong Yi Autonomous Prefecture in the North of Yunnan Province, China, with a branch of Yi nationality named Luoluopu with a population of nearly 3000 living there, is famous for its Yi embroidery, which attracts most attention in Yunnan.

\section{Features of Yi embroidery at Zhizuo}

Influenced by the geographical environment, customs and cultures, Zhizuo's Yi embroidery formed its own unique characteristics. One of the characteristics of Yi ethnic embroidery is: the embroidered pictures are mainly of flowers, animals like birds and tigers, with natural designs and strong, contrasting colors. The styles and pattern of Yi embroidery in different regions in China varies a lot due to different Yi branches, various styles of clothes, different lifestyles, cultural levels, natural environments and geographical conditions and climatic conditions.

Embroidery technique of Yi ethnic group is much developed, and is widely used in making Yi clothing adornments. This is another feature of Zhizuo Yi Ethnic embroidered Costume.

Embroidery of Zhizuo Yi is usually used in decorating the headband, waistband, apron, and some rapid-wearing parts such as the border of the front, the round shoulder, the lower hem, the wristband, the bottom of trouser legs, the edge of the skirt, sleeve, etc., being both decorative and practical.

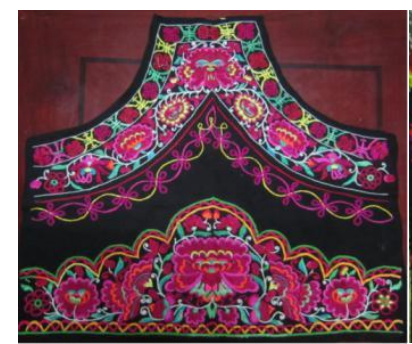

Yi Embroidered Apron

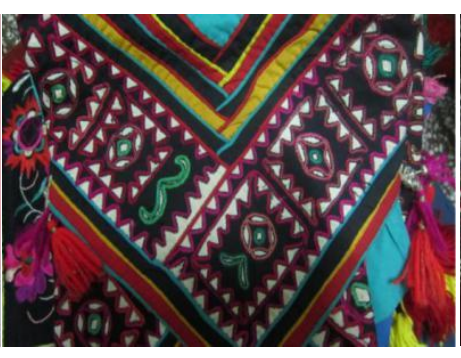

The edge of Yi embroidered waistband

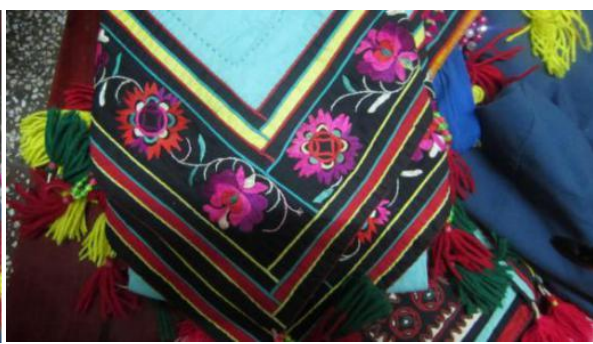
Similar with embroidery techniques of other ethnic groups, Zhizuo Yi embroidery techniques include satin
stitch/plain embroidery, split stitch, cross-stitch work, chain stitch, long and short stitch, buttonhole stitch, applique and so on.

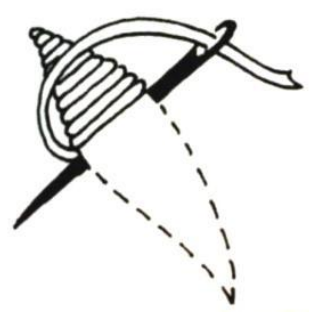

Satin Stitch/Plain embroidery

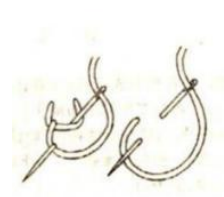

Chain Stitch

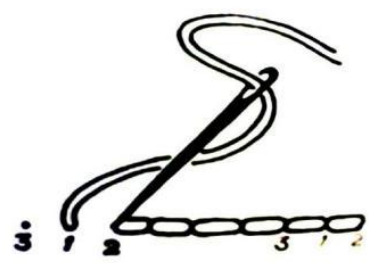

Split Stitch

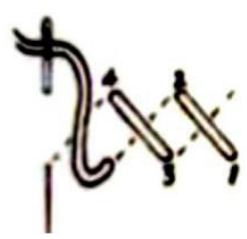

Cross Stitch
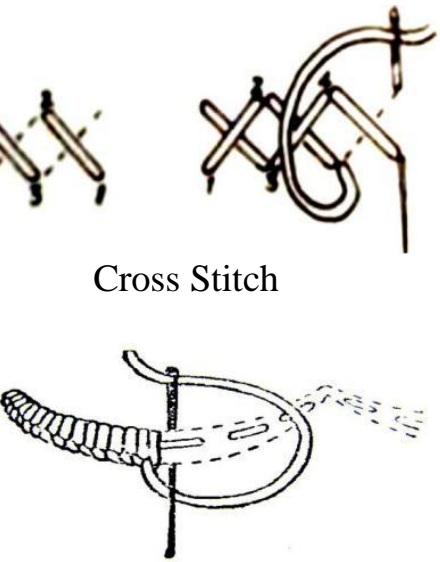

Buttonhole Stitch 


\subsection{Pattern features and Connotation at Zhizuo}

For thousands of years, together with the other members of the big folk family, Yi ethnic group have created splendid embroidery culture. And embroidery becomes an important part of Yi costumes. Yi embroidery is characterized by its elaborate embroidering styles, creative patterns, bright colors, and sturdiness and durability. The patterns feature a wide range of subjects, including various sorts of colorful natural scenes, auspicious patterns, and abstract geometric patterns, with certain particular symbolic meaning.

\subsubsection{Natural scene patterns}

Traditional natural auspicious patterns are widely used to symbolize popular themes at Zhizuo: Camellia, a symbol of auspicious, beautiful and generous, is a common embroidery pattern embodies primitive elements of Yi ethnic group. Rhododendron delavayi Franch, regarded as the embodiment of Yi ancestor by Yi people, is considered the most beautiful mascot and a symbol of triumph over evil. To embroider Rhododendron delavayi Franch on their clothing is to get ancestors' blessing in Yi people's mind. Pomegranate flowers are the symbol for fertility. Peonies for splendor, wealth, prosperity, honor, smart, beautiful, happiness and the symbol of spring. Copper coin flowers are the symbol of great wealth, expressing their yearning for a better life. Lotus is the symbol of auspicious, pure. Fish for fecundity. Birds like magpie for bringing good news. Butterflies are the symbols of happiness, animals like tiger, ox, etc., all these are profound and lifelike. It can satisfy people's attachment to nature, and the psychology of returning to original nature. It conveys the harmony of relationship between human and nature.

\subsubsection{Auspicious patterns}

Some auspicious patterns of Yi embroidery, as a "meaningful form", containing rich connotation, with the characteristics of end to end, no beginning nor end, is used as a good luck sign and has a meaning of continuous "riches and honor", wealth and honor, prosperous and endless. They are commonly seen in Yi areas.

\subsubsection{Geometric patterns}

Octagon design is one of the more common geometric lines on Zhizuo Yi's pants' edges and on insoles, with the characteristics of central symmetry and axisymmetry. It has a meaning of dealing with people intelligently. And for Octagon design, cross-stitch is commonly used. Although done with some geometric or other forms of transforming treatment, all are closely related to their reality, and the starting point of their ideas for a better life is just existed in such a reality of survival. They are used frequently in Yi embroidery in many Yi mountainous areas like Zhizuo. Luoluopu people there has created a colorful, unique and self-contained embroidery costume culture, which consists of splendid turban, collar ornament, waistband, bellyband and embroidered cotton shoes, etc.

\subsubsection{Decorative patterns}

One of the features of Zhizuo Yi embroidery is its traditional and typical pattern. The design patterns used for their costumes are mostly inspired by the substances in nature, like the sun, the moon, stars, wave, mountain, plants and animals, reflecting the Yi's respect and love for nature. The patterns are beautiful, elegant and meaningful.

Some patterns on their colorful embroidered cockscomb cap, aprons, shoes and shoe-pads, pants, vest and dark sheepskin capes imply the moon, stars and clouds and water, plants and animals by employing bold color schemes and rich bright colors such as the colors of red, yellow and black, the three main colors used in Yi embroidery, which gives a back-to-nature feeling of plainness, boldness and implicating graceful cultural deposits. It differs from other Yi embroideries scattered in different regions in China due to various costume designs of different Yi branches. It is also their distinctive features.

\section{Conclusion}

Yi people have their own understanding of cultural connotations on all kinds of embroidery patterns, Embroidery not only reflects people's pursuit for a better life, but also reflects the influence caused by beautiful, pure, fresh, harmonious and quiet living environment and natural environment. It can directly represent Yi people's national character, living custom and national religion, or indirectly implies Yi people's thoughts and feelings and good wishes of life, reflects their understanding and reverence of nature, and embodies national character and national cultural psychology of Yi. It is not only a reflection of their unique national identity psychology, but also an expression of the harmony of man and nature. 


\section{Acknowledgment}

This work was supported by National Social Science Foundation of China.

\section{References}

A. Liley Mills and Boon. Craft of Embroidery.

Barbara Snook. (1972).The Creative Art of Embroidery. Hamlyn House: Hamlyn Publishing Group Limited.

Linli Chen. (2014). Research on Yi Embroidery Craft in Zhizuo of Yongren County[D]. Kunming:Yunnan University.

Linli Chen. (2014). Inheritance Significance of Yi Embroidery in Zhizuo of Yunnan as an intangible Cultural Heritage. Thinking, No 1, 2014.

S.F.A Caulfield and B.C.Saward. (1903). Dictionary of Needlework. London: L. Upcott Gill. 